\title{
Revisie in vertaling: wanneer en wat
}

\author{
Hella Breedveld \\ Huub van den Bergh \\ Universiteit van Utrecht \\ Utrechts instituut voor linguïstiek OTS
}

Translators often go through their texts several times before considering their translations 'done'. In most translation process research the different runs through the text after producing a draft version of the translation are considered as a single revision stage of the translation process. If, however, the factor time is taken into account, it might be expected that the revision activities a translator performs differ in nature and function depending on the moment where they occur during the translation process. The present article is a search for describing and understanding revision processes based on this view. Revision activities in the think-aloud protocols of five translators are analysed with regard to cognitive context and text processing characteristics. Results show that there is little evidence that revision activities vary during the translation process. Revision activities seem to occur at random throughout the translation process and appear to be triggered locally.

\section{Inleiding}

Vertalen is een complexe activiteit. Tussen het verwerken van de brontekst in al zijn facetten, en het produceren van een doeltekst die voldoet aan de verschillende eisen die daaraan (al dan niet expliciet) zijn gesteld, ligt een ingewikkeld proces van problemen oplossen en beslissingen nemen. De vertaler werkt zowel op het seriële niveau van opeenvolgende woorden van de tekst als op het structurele niveau van de tekst (in context) als geheel (Holmes 1988a). Het is dan ook onwaarschijnlijk dat een vertaling in één enkele keer in definitieve vorm op papier of scherm verschijnt.

as a rule, translators do not attain a result which they would regard as acceptable (under the norms they have subjected themselves to) in one fell swoop, but rather in a series of moves. This practice enables the translator to practice self-corrective feedback involving a constant self-monitoring process. (Toury 1995:184)

Reviseren is dus een cruciaal onderdeel van het vertaalproces. Des te opmerkelijker is het dat in het toegepaste vertaalonderzoek revisievaardigheid slechts in impliciete zin aan de orde komt, ingebed in de eisen waaraan de vertaler moet voldoen. Zo noemt Kussmaul (1995) het vermogen de eigen (creatieve) vertaaloplossingen adequaat te evalueren, meent Nord dat de vertaler een skoposgerichte analyse van de beoogde doeltekst dient te maken die 
vervolgens leidraad voor de doeltekstproductie is (1991), en noemt Tirkkonen-Condit (1997) het ontwikkelen van kritisch vertalersbewustzijn. Hatim \& Mason (1997) volgen voor hun beschrijving van vertaalvaardigheid de in vertaaltheorie gebruikelijke driedeling van het vertaalproces: brontekstverwerking, transfer en doeltekstverwerking. De vaardigheden waarover de vertaler op het niveau van doeltekstproductie moet beschikken definiëren ze als volgt:

Establishing intertextuality (genre/discourse/text), establishing situationality (register, etc.), creating intentionality, organising texture (lex. choice, syntactic arrangement, cohesion and structure) [and] balancing informativity (static/dynamic) in terms of estimated impact on target text readership. (Hatim \& Mason 1997:205)

Ook hier dus een impliciete erkenning van het belang van revisie. Gegeven het belang van revisie en daarmee van revisievaardigheid in vertalen is het verwonderlijk te noemen dat er zo weinig over dit onderdeel van het vertaalproces bekend is en dringt zich de vraag op hoe revisie in een vertaalproces voorkomt. Wat voor een subproces ís revisie eigenlijk? Is het een apart onderdeel van het vertaalproces, of is de activiteit geïntegreerd in de vertaalhandeling? Wat maakt dat een vertaler gaat reviseren? Welke rol speelt revisie als cognitieve activiteit in het vertaalproces van een vertaler? En wanneer is een revisieactiviteit 'succesvol'? Mijn onderzoek naar de verwevenheid van cognitieve processen in vertalen en schrijven gaat over deze vragen.

\subsection{Revisie in modellen}

De vraag naar de aard van revisieactiviteiten in het vertaalproces is vanuit vertaalwetenschappelijke hoek nog niet gesteld. Illustratief in dit opzicht zijn twee hierna beschreven modellen van het vertaalproces. Beide claimen een weergave te zijn van het vertaalproces, terwijl ze allebei ook sterk theoretisch en tekstgeoriënteerd zijn, en niet onmiddellijk in cognitieve termen zijn gevat. Noch in de theorievormende benadering van Holmes, noch in de functionalistische visie van Nord speelt revisie een rol als afzonderlijk deel van het vertaalproces.

Volgens de 'mapping'-theorie van Holmes (1988b) werken vertalers gelijktijdig op serieel niveau en structureel niveau. Op serieel niveau volgt de vertaler de lineaire organisatie van de brontekst bij het interpreteren daarvan en bij het produceren van de doeltekst, op structureel niveau maakt de vertaler mentale representaties ('maps') van zowel de brontekst als de te realiseren doeltekst. De mentale representaties zijn van invloed op de realisatie van de doeltekst. In dit model wordt niet zichtbaar of en op welk moment evaluaties of revisies in het proces een rol spelen. Opvallend is het lineairprogressieve karakter ervan: de vertaalhandeling beweegt van de brontekst naar de doeltekst, en er is geen plaats ingeruimd voor terugkoppelingen, controles of revisies. 
Die terugkoppeling is duidelijker aanwezig in het model van Nord (1991). Dit is een circulair model, waarin de vertaalhandeling begint met een analyse van de te realiseren doelen, om door te gaan met brontekstverwerking en -analyse, omzetting van de brontaaluitingen in doeltaaluitingen, en tenslotte terugkomt bij de analyse van doeltekstverwachtingen om deze te toetsen aan de gerealiseerde doeltekst en de verwerkte brontekst. De taak van de vertaler is volgens Nord om de elementen van de brontekst in overeenstemming te brengen met de doeltekstskopos (1991:33). Ook het model van Nord is een ideaalmodel, dat bovendien vooral didactisch en prescriptief geïnspireerd is, en toegespitst is op de rol van übersetzungsrelevante Textanalyse. Revisie van de vertaling (of van vertaalde tekstsegmenten) gebeurt bij Nord ergens in die cirkel: als analyses, probleemoplossingen en omzettingen tot de realisatie van doeltekst(fragmenten) hebben geleid, kan een nieuwe analyseslag revisies tot gevolg hebben. Binnen dit globale vertaalproces zijn er bij Nord voortdurend kortere terugkoppelingen van de brontekstskopos naar de brontekst en van de doeltekstskopos naar de doeltekst.

Hoewel ongelijksoortig, en slechts een greep uit de modellen die de vertaalwetenschap rijk is, illustreren deze modellen wel de impliciete status van revisie in vertaling, en vormen zij een mogelijke verklaring voor het feit dat er nog zo weinig onderzoek naar dit onderdeel is gedaan.

In het schrijfprocesonderzoek heeft men hierin duidelijk andere keuzes gemaakt. Hier is revisie juist een van de meest onderzochte deelprocessen (Van den Bergh \& Rijlaarsdam 2001). In modellen van het schrijfproces is revisie een apart - en te onderzoeken - deelproces. Veel onderzoek op dit terrein richt zich op beginnende schrijvers en hun vermogen om hun eigen teksten te verbeteren aan de hand van eigen beoordeling daarvan of van commentaren van een docent of medeleerling.

Volgens Bereiter \& Scardamalia (1987) bestaat een revisieproces uit drie onderdelen, compare, diagnose, operate. Revisie onderbreekt het schrijfproces om de tekst te herzien en gemaakte keuzes te heroverwegen en eventueel te wijzigen, waarna de schrijver terugkeert naar het produceren van nieuwe tekst.

Ook in het werk van Flower \& Hayes (1980) en in Hayes et al. (1987) vormt revisie een belangrijk onderdeel van het schrijfproces. Zij onderscheiden twee mogelijke strategieën die schrijvers kunnen volgen wanneer zij reviseren, een detect/rewrite- en een diagnose/revise-strategie. De vraag waarop ze een antwoord proberen te vinden is, hoe het kan dat iedereen, schrijvers en docenten, revisie een belangrijk onderdeel van het schrijfproces vinden, maar dat onderzoek naar de effecten van revisie niet uitwijst dat meer reviseren ook betere teksten oplevert.

\subsection{Revisie in empirisch onderzoek}

Terwijl revisie dus in theoretische modellen van het vertaalproces nauwelijks een rol speelt, onderscheidt veel empirisch vertaalonderzoek wel een aparte revisiefase in het vertaalproces, naast een voorbereidende fase en een schrijf- 
fase (zie bijvoorbeeld Krings 1986; Gerloff 1988; Jääskeläinen 1999; Tirkkonen-Condit 1989). Toch betekent dit in de meeste gevallen niet dat die gepostuleerde fases van het proces ook afzonderlijk worden geanalyseerd. Uitspraken over 'het vertaalproces' gaan meestal over 'het proces als geheel' (Jääskeläinen 1999), of over alleen de 'productiefase' (Krings 1986; Lörscher 1991; Tirkkonen-Condit 1989).

De enige studie waarin revisie expliciet aan de orde komt is Gerloff (1988). Gerloff observeerde onder andere dat vertalers die betere teksten produceerden meer hadden gereviseerd dan degenen die minder goede teksten produceerden, terwijl niet alle vertalers die veel hadden gereviseerd ook betere teksten maakten. Bovendien observeerde Gerloff dat de grootte van teksteenheden waarin vertalers de tekst verwerkten toenam naarmate de vertaler vaker door de tekst heenging gedurende het proces. Hoewel Gerloff deze twee bevindingen slechts kort aanstipt, zijn ze voor mijn onderzoek een veelzeggend aanknopingspunt.

\subsection{Op zoek naar de temporele dimensie in revisie}

De bevinding van Gerloff dat vertalers grotere teksteenheden verwerken naarmate ze vaker door de tekst gaan suggereert niet alleen dát er gereviseerd wordt, maar ook dat er in de loop van het vertaalproces iets verandert in het proces. Iets vergelijkbaars observeerde ook Séguinot (1997): een vertaler maakt aan het begin van zinnen een ander soort fouten dan aan het eind van zinnen. Séguinot verklaarde dit verschijnsel als een effect van de beperkte capaciteit van het werkgeheugen, waardoor aan het eind van de zin andere inhouden een rol spelen dan aan het begin en concludeerde dat variabiliteit binnen het vertaalproces een nader te onderzoeken onderwerp is.

Deze conclusie van Séguinot laat zich plaatsen in een ontwikkeling die sinds een aantal jaren in het schrijfprocesonderzoek is ingezet. In diverse publicaties is aangetoond dat bepaalde activiteiten van het schrijfproces, zoals het teruglezen van de tekst-voor-zover-geschreven of het plannen van schrijfactiviteiten, in de loop van het proces van functie en aard veranderen. Van den Bergh \& Rijlaarsdam (2001) en Breetvelt et al. (1994) spreken in dit verband van een 'veranderende taakomgeving': naarmate de tekst in wording groeit, verandert de informatie die de schrijver over de tekst en over de schrijftaak heeft. Schrijvers passen hun schrijfproces aan aan die veranderende taakomgeving of aan de veranderende mentale representatie van de tekst. Wanneer het schrijfproces als een veranderende taakomgeving wordt begrepen, betekent dit dat in het schrijfprocesonderzoek de vraag hoe vaak een activiteit voorkomt plaatsmaakt voor de vraag wanneer een activiteit plaatsvindt en met welk effect. Voor revisies geldt dan: niet zozeer de frequentie van revisiehandelingen is van belang, als wel hun functie in relatie tot andere onderdelen van het schrijfproces, en de kwaliteit van de gepleegde revisies.

Op grond van deze overwegingen stel ik in dit artikel de vraag naar de aard van revisiehandelingen uitdrukkelijk in een temporeel perspectief. 
Net als voor schrijven zijn er voor vertalen aanwijzingen dat de vertaaltaak gezien moet worden als een veranderende takomgeving (Breedveld, te verschijnen). Naarmate de doeltekst-in-wording vordert, en de taakuitvoerder, de vertaler, langer met de taak bezig is, verandert de taakomgeving, of de perceptie daarvan door de vertaler, wat tot gevolg zal hebben dat ook het proces verandert. De vraag is nu of voor revisiehandelingen een zelfde soort variabiliteit geldt. De verwachting op grond van het bovenstaande is dat vertalers hun revisiegedrag veranderen als ze vaker door een tekst gaan. De centrale vraag in dit onderzoek is óf ze dat inderdaad doen, en op welke manier.

\section{Dataverzameling en -analyse}

Het voor dit onderzoek verzamelde materiaal omvat hardopdenkprotocollen van vijf vertaalsters van verschillende ervaringsniveaus. Twee vertaalsters zitten in de laatste fase van hun vertaalstudie, drie vertaalsters hebben minimaal twee jaar praktijkervaring als zelfstandig vertaalster. Bij de protocolanalyse is met opzet geen onderscheid gemaakt tussen deze twee groepen. Uit verschillende studies blijkt namelijk dat dit onderscheid allerminst onomstreden is. 'Professionele' of zelfs 'ervaren' vertalers leggen niet bij elke opdracht een eenduidig 'professionele' werkwijze aan de dag, maar passen naar alle waarschijnlijkheid hun gedrag aan de aard van de taak aan (Laukkanen 1996). Bovendien blijkt 'professionaliteit' geen garantie voor kwaliteit van de vertaling (Gerloff 1988; Jääskeläinen 1999). Om deze reden stel ik bij de verwerking van de protocolgegevens een kwalificatie van de proefpersonen uit. Weliswaar zijn voor de hardopdenksessies deelnemers gezocht uit de twee groepen 'novicen' en 'experts', maar deze kwalificaties zullen geen uitgangspunt voor de analyse vormen.

Het gebruik van de hardopdenkmethode als data elicitation technique kent zowel voor- als tegenstanders. Voorstanders claimen dat de methode toegang geeft tot de mentale inhouden in het kortetermijngeheugen van de taakuitvoerder en goed analyseerbaar materiaal oplevert, met name als het een talige taak betreft (bijvoorbeeld Ericsson \& Simon 1993, of voor vertalen Krings 1986). Tegenstanders benadrukken de reactiviteit van de methode, namelijk dat de cognitieve processen van een taakuitvoerder veranderen door hardop te denken, en de onvolledigheid van het aldus verzamelde materiaal (Cooper \& Holzman 1983). Een uitgebreidere bespreking hiervan biedt Smagorinsky (1989). Een pragmatische stellingname in deze discussie is dat ondanks de mogelijke bezwaren, de hardopdenkmethode in ieder geval énig zicht geeft op de ontstaansgeschiedenis van de vertaling, op overwegingen van de vertaler, op aarzelingen, hernemingen, revisies, en op activiteiten die de vertaler tijdens het werken uitvoert. Het hardopdenkprotocol, de uitgeschreven band met alles wat de vertaler tijdens het werken hardop heeft gezegd, valt natuurlijk niet samen met de mentale processen in het hoofd van de vertaler. De doorkijk die vanuit een hardopdenkprotocol wordt verkregen biedt in het beste geval enig houvast voor gemotiveerde gissingen omtrent 
de onderliggende mentale processen, maar is niet gelijk te stellen met 'het' proces.

De fundamentele onmogelijkheid van 'endospectie' door middel van hardopdenkprotocollen, krijgt in mijn onderzoek een plaats door toepassing van een uitermate vereenvoudigd analysesysteem, bestaande uit categorieën die als veruiterlijkt gedrag herkenbaar zijn, zonder aanspraak te maken op onderliggende mentale inhouden. In de categorieën 'Lezen, Productie, Beoordelen, Zoeken en Monitor' zijn onder andere activiteiten gescoord als 'Lezen brontekst (BT), Lezen doeltekst (DT), Formuleren, Schrijven, Reviseren, Beoordelen doeltekst als doeltekst, Beoordelen doeltekst in relatie tot brontekst en Woordenboekgebruik'. Deze activiteiten zijn alle zo 'plat' mogelijk gedefinieerd: Lezen BT, bijvoorbeeld, wordt toegekend als de proefpersoon hoorbaar of zichtbaar de brontekst leest, een uiting wordt als Beoordelen gescoord als de proefpersoon een uiting doet waarin een expliciet oordeel zit, bijvoorbeeld: 'dat is niet goed'. Ook de definitie van Reviseren is eenvoudig: een activiteit heet Reviseren als de vertaalster een eerder geproduceerd en opgeschreven tekstgedeelte wijzigt of vervangt. Concreet komt dit erop neer dat alle als Schrijven gecodeerde segmenten, nadat er eenmaal een eerste versie van een tekstfragment is geproduceerd, als Reviseren worden gecodeerd.

De hardopdenkprotocollen zijn, in navolging van Breuker et al. (1986) opgedeeld in zo klein mogelijke segmenten volgens twee principes. Ten eerste gebeurt de segmentering op grond van pauzes in de spraak: wanneer een vertaler langer dan drie seconden stil is wordt er een segmentgrens geplaatst. Het tweede criterium voor segmentering loopt parallel met de codering en gebeurt op basis van verandering van inhoud van het gesprokene. Wanneer bijvoorbeeld een vertaalster een stukje brontekst leest en vervolgens een vertaling formuleert, wordt daartussen een segmentgrens geplaatst. Deze segmentering staat los van de manier waarop de vertaalsters zelf de tekst opdelen in segmenten met het oog op vertaling daarvan.

In de protocollen zijn bovendien 'fases' in het proces onderscheiden: elke keer dat een vertaler het einde van de tekst had bereikt en opnieuw bij het begin begon voor een nieuwe tekstdoorloop is als het begin van een nieuwe fase aangemerkt. Bij vertaalsters die voordat zij begonnen met vertalen de tekst doorlazen, geldt die eerste doorloop als 'fase 0'. De tekstdoorloop waarbij een eerste versie van de vertaling werd geproduceerd is genummerd als 'fase 1'. Op deze tekstproductiefase volgt een per persoon verschillend aantal revisiefases, die genummerd zijn als fase 2, 3, enzovoort. Fase 2 is dus bij iedereen de eerste revisiefase, fase 3 de tweede, enzovoort.

Omdat de vraag naar variabiliteit van revisieactiviteiten behalve op de cognitieve organisatie van het vertaalproces ook op de inhoud van de revisiehandelingen betrekking heeft (zie paragraaf 4) was er een tweede codering van de protocollen nodig waarin zichtbaar zou zijn hoe de vertaalsters de tekst doorlopen, oftewel hoe groot de teksteenheden zijn waarop elke activiteit betrekking heeft. Deze teksteenheden zijn hier gedefinieerd als 
'woordgroepen', maar niet als 'vertaaleenheden'. In het vertaalprocesonderzoek worden vertaaleenheden meestal gedefinieerd op grond van het concrete handelen van de vertaler. Dat betekent dat verschillende vertalers de tekst in verschillende vertaaleenheden kunnen opdelen. Om de processen van de vertaalsters in dit onderzoek enigszins met elkaar vergelijkbaar te maken, heb ik gekozen voor een zeer eenvoudige notie van 'teksteenheid': de brontekst is lineair en op grond van inhoud opgedeeld in woordgroepen. Vervolgens is per segment van het hardopdenkprotocol aangegeven op welk bereik van de brontekst de activiteit betrekking heeft.

\section{Revisies in temporeel perspectief: Wanneer}

In een model waarin cognitieve activiteiten van het vertaalproces in een onderlinge relatie van functionele afhankelijkheid staan als gevolg van een veranderende taakomgeving, is de vraag relevant wanneer vertalers overgaan tot het reviseren van hun vertaalde tekst. De verwachting dat ze aan het begin van het proces vooral bezig zijn zich te oriënteren op de taak en het produceren van een eerste versie van de vertaling, wordt ondersteund door de patronen waarin de activiteiten Formuleren, Lezen doeltekst en Beoordelen voorkomen. Gemiddeld over de vijf verzamelde hardopdenkprotocollen nemen in de laatste fases van het vertaalproces de activiteiten Lezen BT en Beoordelen sterk toe, terwijl Formuleren licht afneemt (Breedveld, te verschijnen). Daarnaast besteden de vertaalsters aan het begin van het proces meer tijd aan het zoeken van oplossingen in woordenboeken en aan het 'monitoren' van het eigen handelen, dan later in het proces.

Naar aanleiding van deze patronen, is een voor de handliggende verwachting dat revisieactiviteiten vooral zullen voorkomen in de latere stadia van het proces. Bovendien zullen ze steeds vaker volgen op evaluatieactiviteiten.

\subsection{Verdeling over het proces}

Een eerste bevinding is dat maar een zeer klein gedeelte van het volledige vertaalproces uit revisiehandelingen bestaat. Gemiddeld over vijf personen is slechts 6 procent van alle activiteiten een revisieactiviteit, dus een handeling waarbij eerder opgeschreven tekst wordt gewijzigd. De variatie tussen personen loopt van 3 tot 9 procent.

Alle vertaalsters op één na voeren de meeste revisiehandelingen uit in de fase waarin zij hun eerste geschreven versie van de vertaling produceren, fase 1. Gemiddeld valt 60 procent van de revisiehandelingen in deze fase, 20 procent in de fase daarna ${ }^{1}$, en in fase 3 en $4^{2}$ nog eens respectievelijk 12 en 8 procent. Alleen Vertaalster 5 voldoet aan de verwachting dat de meeste revisies in de latere fases van het proces worden uitgevoerd. 


\begin{tabular}{|c|c|c|c|c|c|}
\hline & Tekstprod. & \multicolumn{2}{|c|}{ Revisiefases } & $\mathrm{N}$ \\
\hline $\begin{array}{c}\text { Fase } \rightarrow \\
\text { Vert. } \downarrow\end{array}$ & 1 & 2 & 3 & 4 & totaal \\
\hline 1 & $69 \%$ & $20 \%$ & $11 \%$ & - & 125 \\
2 & $46 \%$ & $4 \%$ & $23 \%$ & $27 \%$ & 26 \\
3 & $69 \%$ & $31 \%$ & - & - & 32 \\
4 & $86 \%$ & $6 \%$ & $7 \%$ & $0 \%$ & 96 \\
5 & $6 \%$ & $43 \%$ & $19 \%$ & $32 \%$ & 68 \\
\hline
\end{tabular}

Tabel 1: Verdeling revisiehandelingen over proces (in \% van revisies)

In absolute zin neemt het aantal revisies per fase over het algemeen dus fors af. Relatief gezien echter, in verhouding tot het totaal aantal handelingen per fase, neemt het aandeel van revisie in de loop van het proces bij vier van de vijf vertaalsters iets toe: van 10 procent naar 11 procent bij Vertaalster 1, van 2 procent naar 7 procent bij Vertaalster 2, van 3 procent naar 8 procent bij Vertaalster 3 en van 1 procent naar 8 procent bij Vertaalster 5 . Ook bij Vertaalster 4 neemt het aandeel iets toe, van 8 procent in fase 1 naar 10 procent in fase 3, maar in de vierde fase voert zij helemaal geen revisies meer uit, waardoor het gemiddelde over de drie 'revisiefases' op 7 procent uitkomt, en dat is een lichte daling ten opzichte van haar fase 1. Opvallend is dat terwijl er in absolute aantallen revisies een aanzienlijk verschil was tussen Vertaalster 5 en de anderen, dit verschil bij een beschouwing van het relatieve aandeel revisies per fase veel minder groot is.

Een stijging na de tekstproductiefase (fase 1) is in overeenstemming met de verwachting dat de latere fases van het vertaalproces revisiefases zijn, maar in deze processen is die stijging zo gering, dat de term 'revisiefase' de lading niet geheel lijkt te dekken. Wanneer 10 procent van de activiteiten in een fase revisiehandelingen zijn, betekent dat dat 90 procent andere activiteiten zijn. De vraag dringt zich dan op wat het betekent dat tijdens de zogenaamde revisiefases zo weinig gereviseerd wordt, en omgekeerd dat in de tekstproductiefase verhoudingsgewijs bijna net zoveel revisiehandelingen voorkomen als in de revisiefases. Hoe komen revisiehandelingen in een vertaalproces voor? Het volgende voorbeeld geeft daar enig zicht op.

Voorafgaand aan dit fragment is de vertaalster begonnen aan een vertaling van de brontekstzin, 'Queste sono le prerogative che hanno consentito alla Alibert una crescita del $44 \%$ superiore a quella del suo stesso setto'. Op het punt waar dit stukje protocol begint, was zij na wat worstelen tot de volgende vertaling gekomen: 'dankzij deze eigenschappen is Alibert erin geslaagd'. Alleen van het begin van de zin staat er dus een vertaling op scherm. Op dat moment begint het productieproces te stagneren, en komt er een beoordeling van de manier waarop deze zin aansluit bij de vorige ${ }^{3}$ :

topkwaliteit en ervaring dat zijn geen eigenschappen / die eigenschappen moeten ook weg () /

toch produceert zij eerst nog een vervolg op de zin, 
een winst te behalen die $44 \%$ hoger ligt dan ()

dat ook onmiddellijk van commentaar wordt voorzien, gevolgd door evaluatie en revisie (cursief/vet) van de vertaling van het woord 'crescita':

het is geen winst het is een groei () / en dan kan behalen ook niet meer () / [tikt 'groei'].

$\mathrm{Na}$ deze revisie leest de vertaalster de hele zin tot nu toe (nog steeds met 'eigenschappen' erin), constateert dat er iets ontbreekt ten opzichte van de brontekst en voegt 'meer' toe, onmiddellijk gevolgd door een negatieve beoordeling daarvan, en een besluit om het zomaar even te laten en eerst de rest van de zin te vertalen.

dankzij deze eigenschappen [onhoorbaar] groei te behalen () / ehm even kijken hoor / erin geslaagd () / 44\% groei () / nee 44\% meer groei () / te behalen / da's niet goed natuurlijk, maar voorlopig even () / dan () / de sector in zijn algemeenheid () / ehm dan de sector waartoe het bedrijf behoort punt ().

$\mathrm{Nu}$ de zin helemaal op het scherm staat, neemt ze hem opnieuw door, waarbij Beoordelen, Lezen DT, Formuleren en tekst wijzigen (Reviseren) elkaar afwisselen.

nou dit is natuurlijk hier klopt niks van / Dankzij deze (onhoorbaar) () / deze () / eigenschappen () / kenmerken / topkwaliteit dat is geen kenmerk wat is nou kwaliteit is dat () / topkwaliteit ervaring technologisch up-to-date zijn altijd op zoek () / hm hoe moet ik dat nou noemen allemaal bij elkaar () / dit alles misschien gewoon hè waarom niet / [tikt 'dit alles'] () / heeft 't mogelijk gemaakt / heeft ertoe bijgedragen () / ja () / dat () / de firma Alibert SpA (onhoorbaar) () / 44\% meer groei () / wat doe je nou met groei / meer is gegroeid () / [tikt 'is gegroeid'].

$\mathrm{Na}$ de zin nog een paar maal te hebben doorgelezen en op onderdelen te hebben beoordeeld ('is dat nou duidelijk, ja, ik denk het wel...') gaat de vertaalster, zonder nog verder revisies aan te brengen, door met het volgende tekstfragment. In de op deze productiefase volgende tekstdoorlopen leest de vertaalster de zin alleen in de doeltaal door, wat evenmin tot een revisie leidt. De enige wijziging die ze nog aanbrengt is in de voorlaatste tekstdoorloop, als ze de woorden 'de firma' schrapt als gevolg van een wijziging in de voorgaande zin waardoor het bedrijf al in die eerste zin van de tekst wordt geïntroduceerd. In de laatste tekstdoorloop leest de vertaalster de zin uitsluitend in de brontaal door.

Te zien is dat de vertaalster in de zogenaamde tekstproductiefase de zin al grotendeels tot zijn definitieve vorm brengt. Ze onderbreekt haar tekstproductieproces om te reviseren. Ze vertaalt een klein brokstukje tekst (een zinsdeel of woordgroep), en sleutelt daaraan door tot ze tevreden is. Vervolgens begint ze aan een volgend stukje dat ze aan het voorgaande vastplakt, en zo verder. Het produceren van een eerste versie betekent in dit geval dus niet een ruwe kladversie produceren die vervolgens de basis kan 
zijn voor verdere revisies, maar betekent een zo compleet mogelijke vertaling maken, en dat gebeurt in een cyclische beweging van formuleren, schrijven en reviseren.

Daarbij valt in de eerste plaats op dat de vertaalster de tekst voor vertaling in zeer kleine brokstukjes opdeelt, en dat de wijzigingen veelal betrekking hebben op lagere tekstniveaus. Hierin ligt een mogelijke verklaring voor het hoge aantal revisies in de eerste fase. Misschien is het zo dat de vertaalsters tijdens de tekstproductie veel kleine revisies plegen op lagere tekstniveaus, terwijl in latere fases revisies op andere tekstkenmerken betrekking hebben. Deze vorm van variabiliteit komt aan de orde in paragraaf 4, waar het gaat over de tekstniveaus waarop de vertalers werken.

\subsection{Cognitieve context van revisiehandelingen}

De observatie dat het aandeel van revisiehandelingen per fase minder stijgt dan verwacht, kan geïnterpreteerd worden als een indicatie dat er geen specifieke procesgebonden aspecten zijn die bepalen wanneer revisiehandelingen plaatsvinden. Kennelijk kunnen revisiehandelingen op elk willekeurig moment in het proces optreden. In termen van cognitieve modellen zou dit een indicatie kunnen zijn dat revisiehandelingen geen vertaalprocesinterne activiteiten zijn, maar in gang gezet worden door een externe monitor die meeloopt met het proces. Als dat het geval is, zou dat de verwachting plausibel maken dat revisiehandelingen na elke willekeurige handeling van het proces kunnen voorkomen. Zou er sprake zijn van een procesinterne monitor, dan zou de verwachting luiden dat bepaalde activiteiten in het vertaalproces wél en andere géén aanleiding geven tot revisiehandelingen. Dit zou ook betekenen dat voor revisieactiviteiten hetzelfde geldt als voor de meeste andere activiteiten van het vertaalproces, namelijk dat ze in een relatie van functionele afhankelijkheid staan met de andere cognitieve activiteiten van het proces.

De verdeling van de revisieactiviteiten over de rest van het proces geeft hierover niet onmiddellijk uitsluitsel. De in totaal door de vijf vertaalsters uitgevoerde 347 revisiehandelingen komen voor in de context van alle andere activiteiten van het vertaalproces, maar wel duidelijk het vaakst na Lezen DT (20\%), Formuleren (30\%) en Evalueren (18\%), terwijl slechts 1 procent van de revisieactiviteiten volgt op Lezen BT. Uiteraard is het aandeel van elk van de vertaalsters in deze gemiddelden verschillend, en het gebeurt ook dat bij een vertaalster een bepaalde sequentie niet voorkomt, maar zichtbaar is wel dat revisiehandelingen na alle andere activiteiten kunnen voorkomen: er is geen activiteit die nooit vóór een revisiehandeling voorkomt. Met andere woorden: er is geen aanwijzing dat er één bepaalde cognitieve activiteit is die revisie triggert, of omgekeerd dat er géén cognitieve activiteit is die revisie per definitie niet triggert.

Toch is hiermee niet onmiddellijk de hypothese van functionele afhankelijkheid van revisieactiviteiten verworpen. Het leeuwendeel (68\%) 
van de revisieactiviteiten komt immers na drie activiteiten van het proces, Lezen DT, Formuleren en Beoordelen. Tabel 2 laat zien hoe vaak de cognitieve activiteiten van het vertaalproces worden gevolgd door revisiehandelingen. Bijna 50 procent van het hele vertaalproces bestaat uit Lezen DT, Formuleren en Beoordelen samen. Het mag dus eigenlijk niet verbazen dat een groot deel van de revisiehandelingen op deze activiteiten volgt. Rekening houdend met de frequentie van de verschillende activiteiten in het totale proces is de verdeling van revisieactiviteiten over het proces veel vlakker. Zo blijkt nu dat van de leesactiviteiten gemiddeld over het proces niet meer dan 6 procent gevolgd wordt door een revisiehandeling, en dat ook maar 9 procent van de formuleeractiviteiten tot revisie aanleiding geeft. Verhoudingsgewijs worden beoordelingsactiviteiten nog het vaakst gevolgd door een revisie, 12 procent, terwijl ook nu Lezen BT het laagst scoort met 1 procent.

\begin{tabular}{|c|c|c|c|c|c|c|c|c|}
\hline $\begin{array}{c}\text { Act. vóór } \\
\text { revisie } \\
\text { fase } \downarrow\end{array}$ & Pauze & $\begin{array}{c}\text { Lezen } \\
\text { BT }\end{array}$ & $\begin{array}{c}\text { Lezen } \\
\text { DT }\end{array}$ & $\begin{array}{c}\text { Formu- } \\
\text { leren }\end{array}$ & $\begin{array}{c}\text { Schrij- } \\
\text { ven }\end{array}$ & $\begin{array}{c}\text { Revise- } \\
\text { ren }\end{array}$ & $\begin{array}{c}\text { Beoor- } \\
\text { delen }\end{array}$ & Overige \\
\hline 1 & $2 \%$ & $1 \%$ & $7 \%$ & $9 \%$ & $2 \%$ & $7 \%$ & $12 \%$ & $4 \%$ \\
2 & $17 \%$ & $0 \%$ & $7 \%$ & $11 \%$ & $0 \%$ & $6 \%$ & $10 \%$ & $6 \%$ \\
3 & $0 \%$ & $0 \%$ & $5 \%$ & $11 \%$ & $0 \%$ & $7 \%$ & $18 \%$ & $7 \%$ \\
4 & $14 \%$ & $0 \%$ & $4 \%$ & $12 \%$ & $0 \%$ & $14 \%$ & $9 \%$ & $5 \%$ \\
\hline $\begin{array}{l}\text { Gewogen } \\
\text { gemid- } \\
\text { delde }\end{array}$ & $5 \%$ & $1 \%$ & $6 \%$ & $9 \%$ & $2 \%$ & $7 \%$ & $12 \%$ & $4 \%$ \\
\hline $\begin{array}{l}\text { Aandeel } \\
\text { van act. } \\
\text { in hele } \\
\text { proces }\end{array}$ & $5 \%$ & $9 \%$ & $19 \%$ & $19 \%$ & $9 \%$ & $6 \%$ & $10 \%$ & $23 \%$ \\
\hline
\end{tabular}

Tabel 2: Aandeel per activiteit van het vertaalproces dat wordt gevolgd door revisiehandelingen, naar fase van het proces.

De hypothese van functionele afhankelijkheid van cognitieve activiteiten houdt in dat activiteiten van functie veranderen al naar gelang het moment in het proces waarop ze voorkomen. Voor revisie was de verwachting dat deze activiteit meer zou voorkomen in de latere fases van het proces, en dan met name steeds meer na lees-, formuleer- en beoordelingsactiviteiten. Tabel 2 toont dat deze verwachting niet volledig uitkomt. Naarmate het proces vordert, komt Revisie steeds vaker na Revisie zelf voor ${ }^{4}$, terwijl Lezen DT bij elke tekstdoorloop minder vaak wordt gevolgd door Reviseren. Formuleren toont slechts een zeer lichte stijging, van 9 procent in fase 1 naar 12 procent in fase 4, terwijl Beoordelen, dat overal het vaakst gevolgd wordt door revisieactiviteiten, schommelt van 12 procent in fase 1 , via 10 in fase 2 en 18 in fase 3 naar 9 in fase 4. 
Deze gegevens bieden weinig ondersteuning voor de hypothese van functionele afhankelijkheid voor revisieactiviteiten, maar lijken eerder te wijzen in de richting van een willekeurig voorkomen. Toch is het nog te vroeg om deze hypothese te verwerpen. Deze analyse heeft immers alleen betrekking op die momenten in het protocol waarop de vertaalster daadwerkelijk iets aan de tekst veranderd heeft, én daarvan hardop verslag heeft gedaan. Allerlei activiteiten die ook deel uitmaken van het revisieproces zijn daarmee niet in beeld gebracht. Zo laat het huidige materiaal geen uitspraken toe over wanneer een vertaler heeft overwogen om te reviseren.

\subsection{Verschillen tussen personen}

Aan de hierboven beschreven proceskenmerken in termen van gemiddelden kleven uiteraard bezwaren. Vanwege het betrekkelijk kleine aantal observaties bestaat de kans dat het gemiddelde onevenredig wordt vervormd door het gedrag van één persoon. Het is daarom ook zinvol om bovenstaande beschrijving aan te vullen met een aantal opmerkingen over het revisiegedrag van de vijf individuele vertaalsters. Terwijl Vertaalster 1 na gemiddeld 14 procent van de formuleeractiviteiten een revisiehandeling uitvoert, doet Vertaalster 2 dat maar na 3 procent van de formuleeractiviteiten. Bij de andere vertaalsters ligt dat gemiddelde op respectievelijk 8 procent, 16 procent en 5 procent. Voor lezen doeltekst liggen de gemiddelden wat dichter bij elkaar, zodat het gemiddelde van 6 procent uit tabel 2 redelijk goed dit aspect van de processen van de vijf vertaalsters beschrijft. Ook het percentage beoordelingsactiviteiten voorafgaand aan revisie varieert sterk: van 5 procent bij Vertaalster 3 tot 17 procent bij Vertaalster 1.

Bij beschouwing van de verschillen tussen fases, blijkt dat alle vijf de processen een verschillend verloop hebben. Zo neemt bij drie vertaalsters het percentage van formuleeractiviteiten dat gevolgd wordt door een revisiehandeling toe in de laatste twee fases van hun proces, terwijl het bij Vertaalster 3 gelijk blijft en bij Vertaalster 5 alleen in de allerlaatste fase van het proces een stijging vertoont. Het aandeel van Lezen DT voorafgaand aan revisiehandelingen blijft bij de meeste vertaalsters gedurende alle fases van het proces gelijk, maar vertoont alleen bij Vertaalster 4 een piek in de tweede fase. Het aandeel van beoordelingsactiviteiten voorafgaand aan Revisie, dat gemiddeld over de vijf vertaalsters toeneemt in de loop van het proces, vertoont bij alle vertaalsters een andere curve. Bij Vertaalster 4 ligt het aandeel gedurende de eerste drie fases van het proces iets boven haar gemiddelde, om in de laatste fase terug te vallen tot 0 . Bij twee andere vertaalsters ( 1 en 2) is het aandeel in de eerste en de laatste fase van hun proces hoog, en in de tussenliggende fases zeer laag of afwezig, terwijl bij Vertaalsters 3 en 5 Beoordelen vrijwel geen rol speelt in de eerste fase van het proces, maar het aandeel daarna geleidelijk stijgt naar bovengemiddeld.

Deze verschillen binnen de processen van individuele vertaalsters geven een aanwijzing dat het vruchtbaar kan zijn om het handelen van iedere vertaalster afzonderlijk in het licht van haar proces als geheel te beschouwen. Terwijl een beschrijving van de gemiddelden nauwelijks zicht gaf op 
enige vorm van functionele afhankelijkheid van revisieprocessen, lijkt daarvan binnen de individuele processen wel sprake te zijn.

\section{Tekstbehandeling bij revisie}

Uit bovenstaande analyses komt het globale beeld naar voren dat revisies vooral lokaal en ad hoc worden uitgevoerd. Het is echter goed mogelijk dat weliswaar de cognitieve context van revisie gedurende het hele vertaalproces gelijk is, maar dat de tekstelementen waarop de revisiehandelingen betrekking hebben wel veranderen naarmate de vertaling zijn voltooiing nadert. Bijvoorbeeld zou het kunnen dat de teksteenheden waarop de vertaler revisies uitvoert van omvang veranderen. Ook is het denkbaar dat de vertaler bij het reviseren vaker afwijkt van de lineaire volgorde van de tekst. Naarmate het proces vordert zal de vertaler immers een sterkere mentale representatie opbouwen van de tekst, en meer op dat niveau gaan werken dan op het niveau van de concrete organisatie van de fysieke tekst. Om zicht te krijgen op deze vormen van variabiliteit in het vertaalproces, is het nodig te kijken hoe de vertaalsters tijdens het vertalen door de tekst gaan.

\subsection{Teksteenheden}

Evenals in het onderzoek van Gerloff (1988) neemt ook in mijn onderzoek de omvang van teksteenheden waarin gewerkt wordt in de loop van het proces toe. In de eerste fase is het aandeel teksteenheden van vijf of meer woordgroepen nog maar 5 procent, in de loop van het proces neemt dit aandeel toe tot 19 procent. Dit geldt echter niet voor revisiehandelingen. Bij deze activiteit blijft het aandeel van grotere teksteenheden gedurende het hele proces min of meer gelijk. Pas in de laatste fase is een verschuiving waarneembaar naar iets grotere teksteenheden (drie of vier woordgroepen naar $30 \%$ ).

\begin{tabular}{|l|c|c|c|c|c|c|c|c|}
\hline & \multicolumn{4}{|c|}{ Revisiehandelingen } & \multicolumn{4}{|c|}{ Overige activiteiten } \\
\hline Aantal woordgroepen $\rightarrow$ & & & & & & & & \\
Fase $\downarrow$ & $1+2$ & $3+4$ & $5+$ & $\mathrm{N}$ & $1+2$ & $3+4$ & $5+$ & $\mathrm{N}$ \\
\hline I & $86 \%$ & $12 \%$ & $2 \%$ & 109 & $88 \%$ & $8 \%$ & $5 \%$ & 1735 \\
II & $86 \%$ & $12 \%$ & $2 \%$ & 42 & $72 \%$ & $18 \%$ & $10 \%$ & 427 \\
III & $81 \%$ & $15 \%$ & $4 \%$ & 26 & $63 \%$ & $22 \%$ & $15 \%$ & 279 \\
IV & $65 \%$ & $30 \%$ & $5 \%$ & 20 & $60 \%$ & $21 \%$ & $19 \%$ & 177 \\
\hline
\end{tabular}

Tabel 3: Verdeling van teksteenheden (in aantallen woordgroepen) over revisiehandelingen en overige activiteiten.

Dit is echter geen sluitende aanwijzing dat revisiehandelingen uitsluitend een lokaal karakter hebben. In de cognitieve psychologie is het van menselijk probleem-oplossen bekend dat wanneer iemand tijdens een takuitvoe- 
ring op problemen stuit, de cognitieve verwerking in kleinere eenheden verloopt dan wanneer er geen problemen zijn. In de hardopdenkprotocollen van de vertaalsters is mooi te zien hoe de verwerking in de productiefase in kleine eenheden verloopt, terwijl in de latere fases grote stukken van de tekst achter elkaar worden doorgelezen. Wanneer er een probleem wordt ontdekt verloopt de verwerking onveranderlijk in kleine eenheden. In de latere fases van het vertaalproces neemt het aantal problemen af (of het aantal opgeloste problemen toe) zodat er steeds meer tekst in grote eenheden wordt gepasseerd. Probleempunten en daarop gepleegde revisies blijven in kleine eenheden verwerkt worden.

\subsection{Tekstdoorloop}

Tot nu toe wijzen dus nog steeds alle tekenen op een lokale tekstbehandeling door de vertaalsters. We hebben echter nog niet gekeken hoe de vertaalsters tot hun revisies komen. Reviseren zij uitsluitend tekst waarop zij op dat moment hun aandacht hebben gericht (lineair) of is hun mentale representatie van de tekst zodanig dat zij bij het reviseren meer de tekst als geheel in het oog houden. In dat laatste geval verwachten we zogenaamde 'aandachtssprongen' door de tekst, waarbij de vertaalster niet langer de lineaire organisatie van de tekst volgt, maar volgens een andere logica de tekst sprongsgewijs doorloopt, en over zinsgrenzen heen werkt. Alle protocollen vertonen dergelijke momenten. Grofweg bevatten de protocollen vier manieren waarop de vertaalsters een aandachtssprong door de tekst maken.

Bij het eerste type aandachtssprong loopt de vertaalster tijdens haar vertaalproces vast op een probleem, verlegt haar aandacht naar een ander tekstgedeelte, dat zij alleen leest, springt vervolgens terug naar waar ze gebleven was en wijzigt al dan niet de eerder opgeschreven tekst en gaat door met het proces 5 .

Dankzij deze xxxx () / deze () / eigenschappen () / kenmerken / [sprong naar zin ervoor] topkwaliteit dat is geen kenmerk wat is nou kwaliteit is dat () / topkwaliteit ervaring technologisch up-to-date zijn altijd op zoek () / hm hoe moet ik dat nou noemen allemaal bij elkaar () / dit alles misschien gewoon hè waarom niet / [typt 'dit alles']

Bij het tweede type loopt de vertaalster vast op een probleem, springt terug naar een ander tekstgedeelte, wijzigt dat, en gaat weer verder waar ze gebleven was.

ampia gamma / heb ik al gehad da's een assortiment / bovendien wil hij kunnen kiezen [uit een groot assortiment nieuwe en traditionele recepten] / die zin ervoor / kunnen kiezen uit / ah assortiment kan ik weglaten / kunnen kiezen uit kunnen kiezen tussen () / kiezen tussen / tussen / tussen nieuwe en traditionele gere- / kiezen nee tussen niet / uit / tussen doe je als je twee dingen moet kiezen / bovendien wil hij kunnen kiezen uit nieuwe en traditionele gerechten / de Italiaanse pastaproducent heeft ehm () / heeft met deze gunstige () / heeft met deze gunstige marktsituatie een eh groot assortiment producten op de markt gebracht. 
Bij deze twee typen aandachtssprongen is er een duidelijke relatie tussen het tekstgedeelte waar het proces stokt en het gedeelte waar de vertaalster vervolgens haar aandacht op richt. Bij het eerste type zoekt de vertaalster input voor de probleemoplossing elders in de tekst, bij het tweede type lost zij het probleem op door elders in de tekst iets te wijzigen.

Bij het derde type aandachtssprong is de relatie met het probleem minder duidelijk. De vertaalster 'herinnert' zich een eerder opgetreden probleem en richt daar haar aandacht op, zonder dat het tekstgedeelte waarmee zij bezig is daartoe zichtbaar aanleiding geeft:

se infatti la pasta ripiena secca ha raggiunto / als droge gevulde pasta / een zekere verzadiging heeft bereikt / [volgt woordenboek actie, eindigend in een oplossing voor 'prerogativa'] nou dan gaan we even zo / dit zijn de xxxx / dit zijn de () / eigenschappen / die Alibert in staat hebben gesteld een groei van / een groei van $44 \%$ meer te verwezenlijken dan in haar eigen sector / nou het krijgt niet de schoonheidsprijs / oh nou ok / nou dus eh / als eh / gatsie droge gevulde pasta en verzadiging afschuwelijk () / een zekere marktverzadiging () / dat klinkt wel wat beter / [typt 'marktverzadiging'].

In dit geval lijkt er eerder sprake van een soort relief-strategy: de vertaalster richt haar aandacht af van een probleem waar zij op dat moment geen raad mee weet, en neemt als afleiding een ander probleem dat nog in haar bewustzijn sluimert. Wanneer zij vervolgens weer naar het eerste probleem (verzadiging) terugkeert, formuleert zij vlot een oplossing waar ze wel tevreden over is (marktverzadiging). Misschien is dit ook te zien als een variant van de ontspanning tijdens het vertalen die Kussmaul (1995) noodzakelijk acht voor het ontstaan van creatieve vertaaloplossingen.

Ten slotte is er nog de 'losstaande' sprong, waarbij de vertaalster eigenlijk even nergens in het bijzonder mee bezig is, bijvoorbeeld omdat zij net een zin of een tekstversie heeft afgerond. Het komt voor dat op zo'n moment de vertaalster besluit dat zij nog even een bepaald probleem op moet lossen, en daar in de tekst naartoe gaat .

De hier beschreven aandachtssprongen, en dan met name de eerste twee typen, zijn van een ander niveau dan de meer automatische hernemingen van het type 'als je het niet meer weet, ga dan een stukje terug en probeer het opnieuw', zoals beschreven door onder andere Séguinot (1989). Ook deze werkwijze is in de protocollen terug te vinden, maar de 'automatische' procedures overschrijden nooit een zinsgrens. De vertaalster loopt bij het formuleren of opschrijven van tekst vast, en begint dan opnieuw bij het begin van de zin voor een nieuwe poging. Zo'n herstart is niet als een 'aandachtssprong gescoord'.

Een aandachtssprong over een zinsgrens heen, en in ieder geval wanneer die van het eerste of tweede type is, lijkt ingegeven door een bewuste strategie met een duidelijk doel. De vertaler loopt op een probleem, achterhaalt wat dat probleem is en waar de oplossing ervoor ligt, dan wel informatie die kan helpen bij het vinden van een oplossing, en zoekt die informatie op. Zo'n strategie is vergelijkbaar met wat Hayes et al. (1986) een diagnose-revise-strategy noemen. Deel van de diagnosestelling voor het pro- 
bleem ligt in het zoeken in de tekst naar gerelateerde passages en daarin een oplossing voor het probleem vinden.

Het huidige materiaal is te beperkt om het voorkomen en de rol van aandachtssprongen nader te duiden in het licht van de rest van het proces. Maar het feit dat dit soort aandachtssprongen voorkomen en bovendien regelmatig tot een revisie leiden is een duidelijke aanwijzing dat de vertalers vertrouwen op een mentale representatie van de tekst, hoewel dus andere indicatoren vooral in de richting van een lokale en seriële werkwijze richten. Mogelijkerwijs kan een nadere bestudering van aandachtssprongen in het vertaalproces meer informatie geven over de manieren waarop vertalers een mentale representatie inzetten bij het smeden en repareren van hun vertaling.

\section{Slotopmerkingen}

De bovenstaande analyses leiden tot de algemene conclusie dat het revisiegedrag van vertalers gedurende het proces nauwelijks verandert. Met andere woorden, hoewel de andere activiteiten van het vertaalproces gedurende dat proces wisselen van functie en van aard (Breedveld te verschijnen), kan dit voor revisieactiviteiten vooralsnog niet worden aangetoond. Mogelijkerwijs is dat een effect van een aantal onderzoekstechnische keuzes. Het onderzoek is verricht op de hardopdenkprotocollen van vijf vertaalsters, die ieder één tekst hebben vertaald. Bij de analyse van het materiaal heb ik me beperkt tot het scoren van 'uiterlijke' categorieën van handelen, zonder te proberen de observeerbare activiteiten te duiden in termen van 'bedoeling' van de vertaler of 'achterliggende gedachte'. Deze keuze heb ik verdedigd met het argument dat het protocol geen rechtstreekse toegang tot cognitieve processen biedt, en dat daarom ook in de analysemethode elke suggestie dat dit wel het geval zou zijn moet worden vermeden. Eenzelfde argument ligt ten grondslag aan de beslissing om in de hardopdenkprotocollen fases te onderscheiden op grond van de tekstdoorlopen die vertalers maken. De tekst die de proefpersonen vertaald hebben, was niet buitengewoon moeilijk. Dat kon ook niet aangezien een al te moeilijke tekst binnen de laboratoriumopstelling en met de beperkte hulpmiddelen die daar beschikbaar waren onwerkbaar zou zijn geweest voor de vertaalsters. Bovendien zou een moeilijker tekst zodanig het werkgeheugen belasten dat de proefpersonen niet meer in staat zouden zijn om hardop te denken.

Deze onderzoekstechnische omstandigheden spelen mogelijk een rol in de gevonden resultaten. In dit stadium van het onderzoek was het vooral de bedoeling een manier te vinden om te denken over de rol van revisieactiviteiten in het vertaalproces. Voor dat doel lijken de gekozen analysemethoden ondanks hun beperkingen geschikt.

Om te beginnen roept het hier beschreven materiaal de vraag op in hoeverre revisieactiviteiten gezien moeten worden als een integraal onderdeel van het vertaalproces of juist als een onderdeel van een apart revisieproces dat parallel loopt aan het vertaalproces zelf. In zijn boek over spraakproductie onderscheidt Levelt een connectionist theory of monitoring van 
een editor theory of monitoring. In het eerste model is de monitorcomponent intern aan de cognitieve activiteiten die een rol spelen bij het produceren van gesproken tekst. De monitor wordt automatisch mee-geactiveerd en wordt bewust zodra een spreekactiviteit spaakloopt. In de editor theory of monitoring loopt er een externe editor parallel aan het spreekproces en komt in actie als er een deelproces is afgerond om de uitkomst van dat deelproces in overeenstemming te brengen met de eerder geproduceerde tekst. Voor revisie in vertalen zijn twee vergelijkbare modellen denkbaar. De in paragraaf 3 beschreven bevinding dat revisieactiviteiten zich anders gedragen dan andere activiteiten van het proces zou een indicatie kunnen zijn dat revisie juist een buiten het vertaalproces staande module is, die na voltooiing van ieder deelproces in actie komt met een beoordeling of er al dan niet gereviseerd moet worden. Tegelijkertijd wijst het lokale en random karakter van de activiteit er mogelijk op dat de revisiecomponent intern is aan het vertaalproces, dus dat bij elke activiteit van het vertaalproces er automatisch en gelijktijdig een controlemechanisme in werking is.

Een andere vraag die uit de resultaten naar voren komt, is of revisiehandelingen wel allemaal over een kam geschoren kunnen worden. In dit onderzoek zijn alle momenten waarop wijzigingen in de reeds geschreven tekst worden aangebracht, gescoord als 'revisiehandelingen'. Dat heeft als voordeel dat er geen interpretatie of weging van de handeling hoefde plaats te vinden, met het risico van interpretatie-effecten. Een nadeel van deze aanpak is echter dat de analyse zo geen informatie geeft over de intentie van de vertaler. In paragraaf 4 heb ik getoond hoe sommige revisiehandelingen volgen op een aandachtssprong door de tekst waaruit blijkt dat aan de revisiehandeling een globaal mentaal tekstschema en een bewuste strategie ten grondslag liggen. Andere revisiehandelingen zijn vooral lokaal ingegeven en lijken eerder automatisch te gebeuren. Het lijkt dus zinvol om onderscheid te maken tussen deze twee vormen van revisie. Wijzigingen van de eerste soort zouden als 'echte' revisiehandelingen getypeerd kunnen worden, terwijl die van de tweede soort misschien eerder onder de noemer 'correcties' vallen. Het verschil tussen die twee zit hem in de mate van strategisch handelen waardoor de tekstwijziging is ingegeven.

De hier gekozen benadering geeft in ieder geval zicht op de organisatie van revisiehandelingen. Een aanvullende analyse van de effecten van revisiehandelingen op de tekst zou inzichtelijk kunnen maken wat het herhaaldelijk wijzigen van tekst in opeenvolgende fases oplevert in termen van vertaalkwaliteit. Het is immers denkbaar dat langer werken geen resultaat meer oplevert als er niet ook anders gewerkt wordt. Deze opmerking gaat op voor minstens één vertaalster in dit onderzoek, die in zeven opeenvolgende fases terugkomt op dezelfde punten in de tekst, zonder dat haar opeenvolgende wijzigingen een substantiële verbetering van de tekst inhouden. Vanaf een bepaald punt in het proces kan daarom de tijd die de vertaalster aan revisie besteedt als verloren worden beschouwd. Uitgebreider onderzoek naar de rol en aard van revisieprocessen in het vertalen kan ook voor de vertaaldidactiek van waarde blijken. Pas als we begrijpen hoe reviseren in zijn werk gaat en wanneer revisieprocessen effectief zijn in termen van bereikte tekst- 
kwaliteit, zullen we in staat zijn een vertaalspecifieke revisiedidactiek te ontwikkelen.

\section{Bibliografie}

Bereiter, Carl \& Marlene Scardamalia (1987). The psychology of written composition. Hillsdale: Lawrence Erlbaum Associates.

Bergh, Huub van den \& Gert Rijlaarsdam (2001). "Changes in Cognitive Activities During the Writing Process and Relationships with Text Quality." Educational Psychology Vol. 21 (No 4), 373-385.

Breedveld, Hella (te verschijnen). "Translation processes in time." Te verschijnen in Target 14(2).

Breetvelt, Iris, Bergh, Huub van den \& Gert Rijlaarsdam (1994). "Relations of writing processes and text quality: When and How." Cognition and Instruction $12,103-123$.

Breuker, Joost A. et al. (1986). "Hardopdenken en Protokolanalyse." Tijdschrift voor onderwijsresearch 11(5), 241-254.

Cooper, Marilyn \& Michael Holzman (1983). "Talking about protocols." College Composition and Communication 34, 284-293.

Ericsson, K. Anders \& Herbert A. Simon (1993). Protocol Analysis. Verbal reports as data. Cambridge: MIT Press (Herziene uitgave van 1984).

Flower, Linda S. \& John R. Hayes (1980). "The dynamics of composing: making plans and juggling constraints." Lee W. Gregg \& Erwin R. Steinberg (eds) (1980). Cognitive processes in writing. Hillsdale, New Jersey: LEA, 30-51.

Gerloff, Pamela (1988). From French to English: a Look at the Translation Process in Students, Bilinguals, and Professional Translators. UMI Dissertation services.

Hatim, Basil \& Ian Mason (1997). The translator as communicator. New York: Routledge.

Hayes, John et al. (1987). "Cognitive processes in revision." Sheldon Rosenberg (ed.) (1987). Advances in applied psycholinguistics: vol. 2: Reading, Writing, and Language processing . New York: Cambridge University Press, 176-240.

Holmes, James S. (1988a). "The Future of Translation Theory: A Handful of Theses.” James S. Holmes (1988). Translated. Amsterdam: Rodopi, 97-102.

Holmes, James S. (1988b). "Describing Literary Translations: Models and Methods." James S. Holmes (1988). Translated. Amsterdam: Rodopi, 81-91.

Jääskeläinen, Ritta (1999). Tapping the process. An explorative study of the cognitive and affective factors involved in translating. Joensuu: University of Joensuu publications in the humanities.

Krings, Hans P. (1986). Was in den Köpfen von Übersetzern vorgeht: eine empirische Untersuchung zur Struktur des Übersetzungsprozesses an fortgeschrittenen Französischlernern. Tübingen: Narr.

Kussmaul, Paul (1995). Training the translator. Amsterdam, Philadelphia: John Benjamins.

Laukkanen, Johanna (1996). "Affective and Attitudinal Factors in Translation Processes." Target 8(2), 257-274.

Levelt, Willem (1989). Speaking: From interaction to articulation. Cambridge, MA: MIT Press.

Lörscher, Wolfgang (1991). Translation Performance, translation Process and translationale strategies - A psycholinguistic investigation. Tübingen: Narr.

Nord, Christiane (1991). Text Analysis in Translation. Amsterdam: Rodopi. 
Séguinot, Candace (1989). “The Translation Process.” Candice Séguinot (ed.) (1989). The Translation Process. Toronto: HG Publications, 21-53.

Séguinot, Candace (1997). "Accounting for Variability in Translation." Joseph H. Danks et al. (1997). Cognitive Processes in Translation and Interpreting. London: Sage, 104-119.

Smagorinsky, Peter (1989). "The reliability and validity of protocol analysis." Written Communication 6, 463-479.

Tirkkonen-Condit, Sonja (1989). "Professional vs. Non-professional Translation: A think-aloud Protocol Study." Candace Séguinot (ed.) (1989). The Translation Process. Toronto: HG Publications, 73-85.

Tirkkonen-Condit, Sonja (1997). "Who verbalizes what. Linguistic analysis of TAP texts." Target 9(1), 69-84.

Toury, Gideon (1995). Descriptive Translation Studies and Beyond. Amsterdam: John Benjamins.

\footnotetext{
${ }^{1}$ Het afwijkende percentage revisies in fase 2 van Vertaalster 2 laat zich verklaren doordat zij de tweede fase gebruikt om snel door de tekst te gaan en de opengelaten problemen op te lossen. Na voltooiing van een eerste versie begint de vertaalster weer bij het begin van de tekst, de opengelaten titel, om daarna de tekst door te lopen op problemen. Omdat er duidelijk sprake is van een tekstdoorloop is deze episode wel als aparte fase gescoord.

${ }^{2}$ Fase 4 betekent hier 'fase vier en volgende fases'. Alleen Vertaalster 5 gaat na fase 4 nog drie keer kort door de tekst, waarbij zij nog enkele revisiehandelingen uitvoert.

${ }^{3}$ De schuine strepen markeren segmentgrenzen in het protocol. De cursief en vet gedrukte gedeelten zijn de als 'reviseren' gescoorde uitingen, namelijk die waarbij de vertaalster reeds opgeschreven tekst wijzigt. Een () markeert een pauze in de spraak. Onderstreepte tekst is de tekst die de vertaalster opschrijft. Tussen vierkante haken [...] staan observaties over niet-geverbaliseerde handelingen van de vertaalster. Met deze observaties zijn de hardopdenkprotocollen aangevuld om het beeld wat vollediger te maken.

${ }^{4}$ Het hoge percentage van $14 \%$ 'reviseren na revisie' in fase 4 bevat echter wel een vertekening als gevolg van het gedrag van één vertaalster. Alleen Vertaalster 5 gaat na de 'echte' fase 4 nóg drie keer door de tekst en pleegt dan ook nog enkele revisies. Andere vertaalsters zijn dan al klaar.

${ }^{5}$ Vaak gaat het ook in de tekstproductiefase in zo'n geval al om een revisie omdat de vertaalster al een bepaalde oplossing had getypt alvorens terug in te tekst te kijken.
} 